\title{
Prevalence and clinical aspects of respiratory syncytial virus $A$ and $B$ groups in children seen at Hospital de Clínicas of Uberlândia, MG, Brazil
}

\author{
TFM Oliveira, GRO Freitas, LZG Ribeiro, J Yokosawa, MM Siqueira', SAR Portes ${ }^{1}$, HL Silveira², \\ T Calegari², LF Costa, OC Mantese ${ }^{2}$, DAO Queiróz/ ${ }^{+}$
}

Laboratório de Virologia, Instituto de Ciências Biomédicas ²Faculdade de Medicina, Universidade Federal de Uberlândia, Av. Pará 1720, Bloco 4C, 38400-902 Uberlândia, MG, Brasil 'Laboratório de Vírus Respiratórios, Instituto Oswaldo Cruz-Fiocruz, RJ, Brasil

Respiratory syncytial virus (RSV) is well recognized as the most important pathogen causing acute respiratory disease in infants and young children, mainly in the form of bronchiolitis and pneumonia. Two major antigenic groups, $A$ and $B$, have been identified; however, there is disagreement about the severity of the diseases caused by these two types. This study investigated a possible association between RSV groups and severity of disease. Reverse transcription-polymerase chain reaction was used to characterize 128 RSV nasopharyngeal specimens from children less than five years old experiencing acute respiratory disease. A total of 82 of 128 samples (64.1\%) could be typed, and, of these, $78 \%$ were group A, and $22 \%$ were group B. Severity was measured by clinical evaluation associated with demographic factors: for RSV A-infected patients, $53.1 \%$ were hospitalized, whereas for RSV B patients, $27.8 \%$ were hospitalized $(p=0.07$ ). Around $35.0 \%$ of the patients presented risk factors for severity (e.g., prematurity). For those without risk factors, the hospitalization occurred in $47.6 \%$ of patients infected with RSV A and in $18.2 \%$ infected with RSV B. There was a trend for RSV B infections to be milder than those of RSV A. Even though $R S V$ A-infected patients, including cases without underlying condition and prematurity, were more likely to require hospitalization than those infected by RSV B, the disease severity could not to be attributed to the RSV groups.

Key words: Respiratory syncytial virus groups - young children - disease severity

Respiratory syncytial virus (RSV) is a common cause of hospitalization and visits to the emergency rooms among neonates and young children, especially in their first years of life (Sangare et al. 2006). It is the principal cause of bronchiolitis and pneumonia in children under six months of age (Queiróz et al. 2002, Calegari et al. 2005). An RSV infection does not produce substantial immunity to subsequent infection; thus, reinfections are common, with the frequency of symptoms decreasing with age (Black 2003). Sequelae from the RSV infection have been observed, which are mostly persistent wheezing, increased airway hypereactivity or atopic asthma (Simoes 2001). Virtually all infants have been RSV infected by the age of two (Parrott et al. 1974). In the first infection, $40-50 \%$ have involvement of the lower respiratory tract, and $1-2 \%$ of previously healthy infants develop severe disease requiring hospitalization (Yun et al. 1995).

No effective vaccine is currently available for prophylaxis, and ribavirin therapy has presented only modest benefits (Walsh et al. 1997). In addition, younger infants

Financial support: Fapemig, CNPq, UFU

+ Corresponding author: dqueiroz@icbim.ufu.br

J Yokosawa's present address: NL Biotechnology LLC, Little Rock, AR, USA

Received 16 November 2007

Accepted 7 July 2008 tend to have a prolonged illness with little response to medications in general (Howidi et al. 2007). On the other hand, palivizumab, a humanized monoclonal antibody (IgG1K) directed against an epitope in the A antigenic site of the F protein of RSV, is effective in reducing both the incidence and severity of RSV infections in highrisk infants (Black 2003). Children at the greatest risk of RSV infection include those born prematurely and those with congenital heart disease or chronic lung conditions or immunocompromised (Welliver 2003). Prevention of infection in these infants for as long as possible is particularly important (Black 2003).

$\mathrm{RSV}$ is a Pneumovirus belonging to the Paramyxoviridae family, with the genome composed of a nonsegmented negative-strand RNA that encodes 11 proteins (Cane 2001). The virus infects the ciliated epithelial cells that line the airways, and their rapid destruction results in the symptoms characteristic of the infection (Black 2003), such as fever, rhinorrhea, cough and wheezing (Park \& Barnett 2002) and possibly acute otitis media (Queiróz et al. 2002). RSV isolates are divided into two groups by antigenic and genetic characteristics: A and B (Anderson et al. 1985, Peret et al. 1998). This has led to the speculation that the specific virus group may affect severity and recurrence of the RSV disease (Straliotto et al. 1994). Studies on the clinical aspects associated with each virus group have provide limited information and conflicting results (Walsh et al. 1997, Imaz et al. 2000, Devincenzo 2004); however, it has become important to understand the possible differences in disease severity between subtypes because more therapeutic and prophy- 
lactic modalities against RSV have become available, and an understanding of such differences may have an effect on treatment strategies (Papadopoulos et al. 2004).

In temperate weather regions, RSV epidemics occur annually in the winter months, whereas in tropical areas, the outbreaks are associated with the rainy season (Cane 2001), and, in semi-tropical areas, the virus circulates mainly during autumn (Vieira et al. 2001, Costa et al. 2006). Both groups circulate concurrently in each epidemic, and group A is the most prevalent in many of the epidemics. Several studies indicate that RSV A and $\mathrm{B}$ alternate in prevalence during successive years (Mufson et al. 1988, Sullender 2000). In Brazil, studies have identified the simultaneous circulation of the RSV groups in different years in the Northern (Mello \& Silva 1992), Northeastern (Moura et al. 2003), Southeastern (Siqueira et al. 1991, Cintra et al. 2001) and Southern regions (Straliotto et al. 2001), but, to date, no epidemiological pattern for each specific RSV group has been established for Central Brazil.

Recently, we reported a study to determine the viral etiology of acute respiratory disease (ARD) in children less than five years of age in Uberlândia (Costa et al. 2006). RSV was the most frequently identified agent in acute lower respiratory infections, accounting for approximately $25 \%$ of the cases. The purpose of this study was to determine the RSV group in the samples in which RSV was detected. Moreover, we attempted to establish whether there was a relationship between a specific RSV group and disease severity by analyzing clinical and demographic features of children with confirmed RSV infections.

\section{PATIENTS, MATERIALS AND METHODS}

Patients and specimens - Since April 2000, respiratory viruses have been investigated by indirect immunofluorescence assay (IFA) in nasopharyngeal aspirates (NPA) of children who were less than five years old, experiencing ARD, and attended the Hospital de Clínicas (HC), Universidade Federal de Uberlândia (UFU), state of Minas Gerais, Southeastern Brazil. The study was approved by the ethics committees of UFU and signed consent was obtained from the parents of each child included in this study. Afterwards, a questionnaire was administered to ascertain information about clinical and demographic data, e.g., age, gender, gestational age, clinical symptoms, and risk factors such as immunodeficiency, chronic respiratory disorders (bronchopulmonary dysplasia, cystic fibrosis), congenital heart disease and prematurity. Also, information on any intensive care unit (ICU) hospitalization, requirement of mechanical ventilation and clinical diagnostic criteria such as signs, symptoms, laboratory data, chest radiographs and the pathologies classified according to WHO (1994) were recorded. Hospitalization was required only for those patients presenting moderate or severe disease. Clinical symptoms were divided into: bronchiolitis, bronchitis (laryngotracheobronchitis, bronchospasm, Pertussis-like syndrome, whooping cough, and bronchitis), pneumonia (bronchopneumonia and pneumonia) and upper respiratory tract infection (acute otitis media, rhinitis, sinusitis, flu and upper respiratory tract infection).
One milliliter of physiologic solution was instilled into the nostril of patients and NPA was collected within five days of the onset of symptoms for viral diagnosis. Nasal secretions were aspirated through a catheter into a mucus trap, which was connected to a vacuum source. The catheter was inserted into one nostril parallel to the palate. A vacuum was applied, and the catheter was slowly withdrawn with a rotating motion. Mucus from the other nostril was collected in the same manner. NPAs were processed and RSV diagnoses were performed according to Queiróz et al. (2002) using an IFA kit (Respiratory Panel I Viral Screening and Identification IFA, Chemicon Internacional, Temecula, CA).

$R S V$ isolation in cell culture - NPAs were inoculated in cell culture (HEp-2 cells; ATCC CCL-23) according to the methods by Queiróz et al. (2002). To confirm the isolation of RSV, regardless of the presence of cytopathic effects, cells were removed from the flasks and tested by an IFA kit, as mentioned above. Cell culture supernatants were used in RT-PCR. Some NPA specimens were not inoculated in cell culture and were tested directly (in natura) by RT-PCR.

RSV molecular characterization - The viral RNA was extracted from $250 \mu \mathrm{l}$ of NPA or $125 \mu \mathrm{l}$ of RSV-infected HEp-2 cells, using Trizol ${ }^{\circledR}$ (Invitrogen Corp, Carlsbad, CA). Complementary DNA synthesis and PCR amplification were carried out as previously described (Stockton et al. 1998). The primers used for group determination were generated against the $\mathrm{N}$ and $\mathrm{P}$ regions of the RSV genome, according to the methods by Stockton et al (1998). Ten microliters of each RT-PCR product was separated on a $1.5 \%$ agarose gel and photographed with ImageMaster ${ }^{\circledR}$ VDS GE Healthcare, after staining with ethidium bromide. RSV strains Long (group A; ATCC VR-26) and CH18537 (group B; ATCC VR-1580), both as positive controls, and water as a negative control, were run together in each RTPCR assay to validate the amplification process and to exclude the presence of contaminants.

Statistical analysis - Data were analyzed by using the WINKS 4.8a program (TexaSoft, Cedar Hill, TX, USA) with a statistical significance level of $p<0.05$. Categorical variables were examined by using the Fisher's exact test (two-tailed) with 95\% confidence intervals (CI). For analyses in which the dependent variable was continuous, non-paired Mann-Whitney was used.

\section{RESULTS}

In approximately seven years, we obtained 475 NPAs from children with respiratory disease who attended the HC. Using IFA, RSV was detected in $26.9 \%$ (128/475) samples, of which 46 were from the pediatric first aid clinic, 39 were from the emergency room, 13 were from the nursery ward, and 30 were from the pediatric ICU. By using RT-PCR with RNA extracted either directly from NPAs or from isolates in cell culture, it was possible to determine the virus group in 82 out of $128 \mathrm{RSV}$-positive samples $(64.1 \%)$; these 82 were further classified into RSV A $(78 \%, \mathrm{n}=64)$ and RSV B $(22 \%, \mathrm{n}=18)$. Testing of in natura samples, i.e., NPAs tested directly in the RTPCR assay, resulted in slightly greater (57.3\%) success 
in determining the RSV group than testing of isolates in cell culture (49.4\%), although only three samples needed to be assayed by both methods.

Regarding the RSV circulation by subtype, Fig. 1 shows that RSV A was detected in all seven years of the study, while RSV B was detected in only four years (2001, 2002, 2003 and 2007), when it cocirculated with RSV A. Furthermore, RSV B was more prevalent in 2003 and 2007. In general, RSV was detected from January to June (mid-summer to late autumn) with higher incidence of cases from April to May. However, in 2001, one case was detected in August, and, in 2006, one case occurred in September.

In terms of gender, $57.8 \%$ (37/64) of the RSV A cases were males, compared with $44.4 \%$ (8/18) RSV B cases. However, the difference was not statistically significant $(p=0.42)$ (Table I). By comparing the age of the patients, RSV A- and B-infected patients presented similar medians (4.0 and 4.2 months old, respectively). For RSV A, $59.4 \%$ of the patients were $<6$ months old, while for RSV $\mathrm{B}$, the rate was $55.6 \%$. However, RSV B was not detected in any patients $<1$ month old (Table I).

Bronchiolitis was the clinical diagnosis more frequently observed in RSV A-infected children (Table II). For clinical severity, RSV B infections tended to be milder than infections with RSV A $(p=0.18)$, and, except in one case, all children with severe disease were less than six months old. One fatal case was registered of an infant presenting with a RSV A-infection at her 9th day in the ICU. For both the requirement of mechanical ventilation (RSV A: 8/64; RSV B: $1 / 18$ ) and of ICU hospitalization (RSV A: 16/64; RSV B: 3/18), no statistical difference was observed between the groups.

A total of $35.4 \%(29 / 82)$ of the RSV-infected patients presented with prematurity and other underlying conditions (RSV A: 22/64; RSV B: 7/18). Fig. 2 shows that, for the 39 hospitalized patients, 53.1\% (34/64) were infected with RSV A, while $27.8 \%(5 / 18)$ were infected with RSV $\mathrm{B}(\mathrm{p}=0.07$; OR 2.95; 95\% CI; median age 2.1 and 3.0 months, respectively). When analyzing children without underlying conditions and/or prematurity, hospitalization occurred in $47.6 \%$ (20/42) of RSV A cases and in $18.2 \%$ $(2 / 11)$ of RSV B cases $(\mathrm{p}=0.10$; OR $4.09 ; 95 \% \mathrm{CI})$. In addition, $66.7 \%(26 / 39)$ of the hospitalized patients were males (RSV A: 23/34; RSV B: 3/5) (Table II).

\section{DISCUSSION}

In this study, we determined the RSV group of specimens collected over approximately seven years from children with respiratory disease. Our results, showing that cases with RSV A predominated over cases with RSV B, are in agreement with the majority of such typing studies (Martinello et al. 2002, Savon et al. 2006). However, one study from 1992 to 1995 in Denmark, reported a predominance of RSV B infections (Johansen et al. 1997).

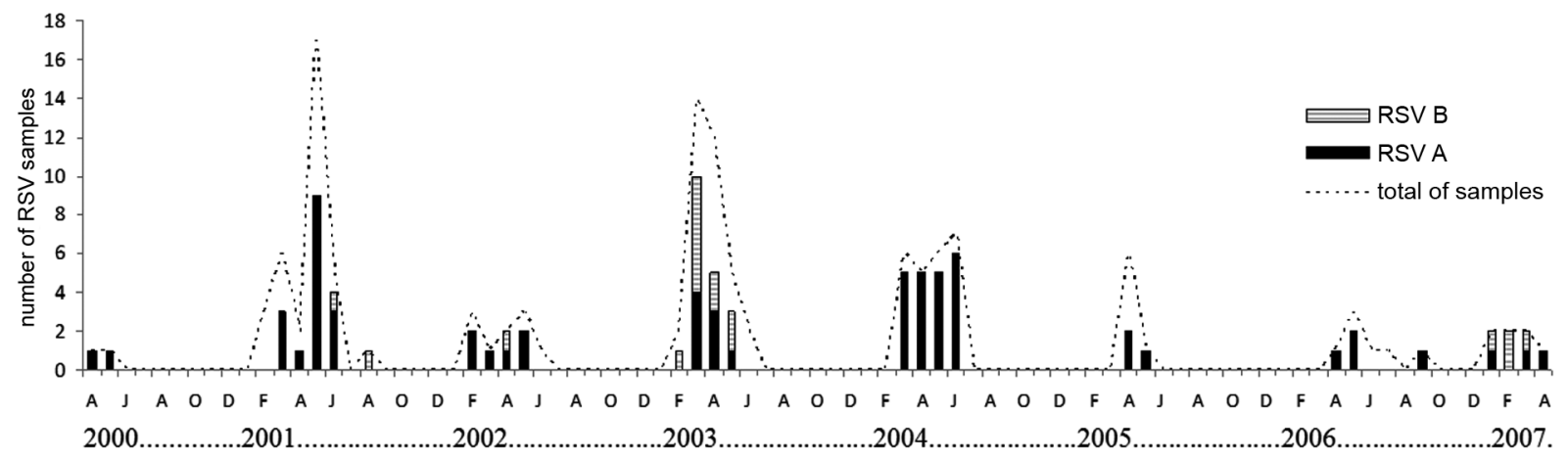

Fig. 1: seasonal distribution of respiratory syncytial virus groups A and B detected in children attended the Hospital de Clínicas, Universidade Federal de Uberlândia, between April 2000 and first months of 2007.

TABLE I

Age and gender distribution according to RSV group of 82 patients who attended the Hospital de Clínicas, Universidade Federal de Uberlândia, with acute respiratory disease from April 2000 to 2007

\begin{tabular}{|c|c|c|c|c|c|c|}
\hline \multirow[b]{2}{*}{ Age (months) } & \multicolumn{3}{|c|}{ RSV A } & \multicolumn{3}{|c|}{ RSV B } \\
\hline & $\mathrm{n}$ & $(\%)$ & Gender $(\overbrace{}^{\Uparrow})$ & $\mathrm{N}$ & $(\%)$ & Gender $(\lesssim)$ \\
\hline$<1$ & 9 & $(14.1)$ & 5 & 0 & $(0.0)$ & 0 \\
\hline $1-3$ & 18 & $(28.1)$ & 11 & 6 & (33.3) & 3 \\
\hline $3-6$ & 11 & $(17.2)$ & 7 & 4 & $(22.2)$ & 2 \\
\hline $6-12$ & 10 & (15.6) & 6 & 3 & $(16.7)$ & 2 \\
\hline$\geq 12$ & 16 & $(25.0)$ & 8 & 5 & $(27.8)$ & 1 \\
\hline Total & 64 & $(100.0)$ & $37(57.8)^{a}$ & 18 & $(100.0)$ & $8(44.4)^{a}$ \\
\hline
\end{tabular}

$a: \mathrm{p}=0.42$. 
TABLE II

Clinical and demographic characteristics according to RSV group and patients

\begin{tabular}{|c|c|c|c|c|c|c|c|c|}
\hline & \multicolumn{3}{|c|}{ RSV A } & \multicolumn{3}{|c|}{ RSV B } & \multicolumn{2}{|c|}{$P$ value } \\
\hline & N (\%) & $\operatorname{age}^{a}$ & gender $(ð)$ & N (\%) & $\operatorname{age}^{a}$ & gender $(ð)$ & $\mathrm{N}^{b}$ & $\operatorname{age}^{c}$ \\
\hline RSV & $64(78.0)$ & 4 & 37 & $18(22.0)$ & 4.2 & 8 & & 0.35 \\
\hline \multicolumn{9}{|l|}{ Illness } \\
\hline bronchiolitis & $30(46.9)$ & 2.0 & 19 & $6(33.3)$ & 2.15 & 4 & 0.42 & 0.78 \\
\hline pneumonia & $5(7.8)$ & 6.0 & 2 & $1(5.6)$ & 4.0 & 0 & 1.00 & 1.00 \\
\hline bronchitis & $9(14.1)$ & 8.0 & 6 & $5(27.8)$ & 14.0 & 2 & 0.18 & 0.51 \\
\hline URTI & $20(31.2)$ & 6.0 & 10 & $6(33.3)$ & 5.5 & 2 & 1.00 & 0.69 \\
\hline \multicolumn{9}{|l|}{ Clinical severity } \\
\hline Mild & $29(45.3)$ & 8.0 & 13 & $12(66.6)$ & 8.5 & 5 & 0.18 & 0.37 \\
\hline Moderate & $18(28.1)$ & 4.3 & 13 & $3(16.7)$ & 1.6 & 2 & 0.38 & 0.27 \\
\hline Severe & $17(26.6)$ & 2.0 & 11 & $3(16.7)$ & 4.0 & 1 & 0.54 & 0.17 \\
\hline Hospitalized & $34(53.1)$ & 2.1 & 23 & $5(27.8)$ & 3.0 & 3 & 0.07 & 0,75 \\
\hline Mechanical ventilation & $8(12.5)$ & 1.7 & 4 & $1(5.6)$ & 2.7 & 0 & 0.68 & 0.33 \\
\hline Intensive care & $16(25.0)$ & 2.1 & 11 & $3(16.7)$ & 4.0 & 1 & 0.54 & 0.24 \\
\hline Risk factor $^{d}$ & $22(34.4)$ & 4.5 & 12 & $7(38.9)$ & 3.0 & 3 & 0.78 & 0.84 \\
\hline
\end{tabular}

$a$ : median in months; $b$ : Fisher's exact test; $c$ : Mann-Whitney; $d$ : underlying conditions and prematurity; UTRI: upper respiratory tract infection.

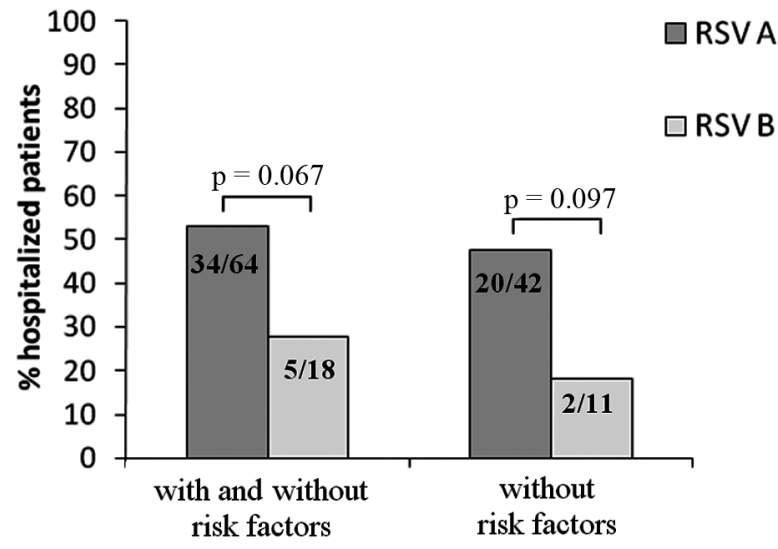

Fig. 2: hospitalized RSV-patients at Hospital de Clínicas, Universidade Federal de Uberlândia, from April 2000 to first months of 2007 with diagnoses of RSV A or RSV B infection presenting moderate or severe disease.

We were able to determine the subtype of approximately $64 \%$ of RSV-positive specimens. Uncharacterizeable specimens also occurred in studies by other authors (Straliotto et al. 1994, Walsh et al. 1997, Cintra et al. 2001). Papadopoulos et al. (2004) typed 59.0\% using RT-PCR directly from NPA samples, and, in this study, using the same method and the same primers sequences (Stockton et al. 1998), we typed 57.3\%. On the other hand, when using RT-PCR in the RSV samples inoculated in cell culture, we were able to characterize $49.4 \%$ of RSV samples. This lower rate could be caused by the lack of virus infectivity or replication in the cells that could have arisen from the long period of specimen storage in freezers at $-70^{\circ} \mathrm{C}$ and/or liquid nitrogen. In addition, it was shown that group B strains tend to grow more slowly in tissue culture, to produce fewer vi- rus particles, and to lose the characteristic of syncytial formation. Therefore, these features could hamper the ability to isolate the virus from clinical specimens and, consequently, the ability to perform group determination (Hall et al. 1990).

The detection of RSV B in alternating years is consistent with other studies (Arbiza et al. 2005, Galiano et al. 2005). Mufson et al. (1987) concluded that an infection by RSV A provides some degree of protection against the reappearance by this same group in the subsequent year. The fact that RSV B was not detected in 2005 and 2006 could be because of the few numbers of clinical specimens obtained in those years. Over 20 years ago, Anderson et al. (1985) described the existence of these two groups, the possibility of their occurrence in the same season and their worldwide distribution.

It is known that male children are more susceptible to severe disease than females (Burr et al. 1993, Queiróz et al. 2002), but the reasons are still unknown. In our study, the majority of RSV A-infected children were male. This result is consistent with that of Sangare et al. (2006), who suggested that being female was protective against RSV hospitalization.

We also found that RSV A-infected patients tended to be slightly younger (median 4.0 vs. 4.2 years), as previously observed (mean 4.6 vs. 5.1 years) (Imaz et al. 2000), and, in the current study, children less than one month of age were infected solely by the group A. In contrast, based on the mean value of ages observed, Papadopoulos et al. (2004) reported a predominance of RSV $B$ infection in the youngest children.

For information on lower tract infections, our data are consistent with those of Garzon and Wiles (2002); they found that bronchiolitis was the most common clinical diagnosis, followed by pneumonia associated with RSV infection. Similar findings were reported by other investigators (Queiróz et al. 2002, Sangaré et al. 2006). 
Papadopoulos et al. (2004), using duration of hospitalization in the severity index, did not find significant differences between the groups. They stated, however, that the length of hospitalization is based on clinical decisions that cannot be controlled. Considering that including hospitalization in the severity index involves more subjective assessments, this factor was not taken into account in this study. Nevertheless, we observed that patients infected by RSV A were more frequently hospitalized than the patients with RSV B. It has been reported that RSV A was more frequently detected and caused more severe disease than RSV B strains in hospitalized infants (Coates et al. 1963). In relation to disease severity, however, others have reported the opposite (Palomino et al. 2004) or even that there was a lack of evidence for differences between groups (Coggins et al. 1998, Cintra et al. 2001), which was similar to what we observed in this study. Also, it was noteworthy that most of the patients with severe symptoms were less than six months old. This observation was in accordance with the results obtained by Imaz et al. (2000) and Cintra et al (2001).

In the comparison of RSV groups with respect to severity of disease, group A infections tended to be slightly more severe than B; however, it was not statistically significant, maybe because of the small sample size or the subjective parameters selected. For instance, more detailed studies of RSV molecular characterization and of the immune response should be done in an attempt to better understand the association with RSV virulence and individual susceptibility.

In conclusion, we did not observe statistical differences in clinical severity between the RSV groups, but we observed a trend for RSV B infection to be milder than RSV A. Even though RSV A-infected patients, including cases without underlying condition and prematurity, were more likely to require hospitalization than those infected by RSV B, the disease severity could not to be attributed to the RSV groups.

\section{ACKNOWLEDGEMENTS}

To Dr. Dean D. Erdman (CDC), for providing some reagents; Dr. Juan Arbiza, for useful discussions; the laboratories of Immunology, Molecular Biology, Parasitology, Physiology and Genetics, UFU, for their equipments; the health care professionals of the Hospital de Clínicas; the patients and their parents.

\section{REFERENCES}

Anderson LJ, Hierholzer JC, Tsou C, Hendry RM, Fernie BF, Stone Y, McIntosh K 1985. Antigenic characterization of respiratory syncytial virus strains with monoclonal antibodies. $J$ Infect Dis 151: 626-633.

Arbiza J, Delfraro A, Frabasile S 2005. Molecular epidemiology of human respiratory syncytial virus in Uruguay: 1985-2001 - a review. Mem Inst Oswaldo Cruz 100: 221-230.

Black CP 2003. Systematic review of the biology and medical management of respiratory syncytial virus infection. Respir Care 48: 209-231.

Burr ML, Limb ES, Maguire MJ, Amarah L, Eldridge BA, Layzell JC, Merrett TG 1993. Infant feeding, wheezing, and allergy: a prospective study. Arch Dis Child 68: 724-728.
Calegari T, Queiróz DAO, Yokosawa J, Silveira HL, Costa LF, Oliveira TFM, Luiz LN, Oliveira RC, Diniz FC, Rossi LMG, Carvalho CJ, Lima AC, Mantese OC 2005. Clinical-epidemiological evaluation of respiratory syncytial virus infection in children attended in a public hospital in midwestern Brazil. Braz J Infect Dis 9: 156-161.

Cane PA 2001. Molecular epidemiology of respiratory syncytial virus. Rev Med Virol 11: 103-116.

Cintra OA, Owa MA, Machado AA, Cervi MC, Figueiredo LT, Rocha GM, Siqueira MM, Arruda E 2001. Occurrence and severity of infections caused by subgroup A and B respiratory syncytial virus in children in southeast Brazil. J Med Virol 65: 408-412.

Coates HV, Kendrick L, Chanock RM 1963. Antigenic differences between two strains of respiratory syncytial virus. Proc Soc Exp Biol Med 112: 958-964.

Coggins WB, Lefkowitz EJ, Sullender WM 1998. Genetic variability among group A and group B respiratory syncytial viruses in a children's hospital. J Clin Microbiol 36: 3552-3557.

Costa LF, Yokosawa J, Mantese OC, Oliveira TF, Silveira HL, Nepomuceno LL, Moreira LS, Dyonisio G, Rossi LMG, Oliveira RC, Ribeiro LZG, Queiróz DAO 2006. Respiratory viruses in children younger than five years old with acute respiratory disease from 2001 to 2004 in Uberlandia, MG, Brazil. Mem Inst Oswaldo Cruz 101: 301-306.

Devincenzo JP 2004. Natural infection of infants with respiratory syncytial virus subgroups A and B: a study of frequency, disease severity, and viral load. Pediatr Res 56: 914-917.

Galiano MC, Palomo C, Videla CM, Arbiza J, Melero JA, Carballal G 2005. Genetic and antigenic variability of human respiratory syncytial virus (groups a and b) isolated over seven consecutive seasons in Argentina (1995 to 2001). J Clin Microbiol 43: 2266-2273.

Garzon LS, Wiles L 2002. Management of respiratory syncytial virus with lower respiratory tract infection in infants and children. AACN Clin Issues 13: 421-430.

Hall CB, Walsh EE, Schnabel KC, Long CE, McConnochie KM, Hildreth SW, Anderson LJ 1990. Occurrence of groups A and B of respiratory syncytial virus over 15 years: associated epidemiologic and clinical characteristics in hospitalized and ambulatory children. J Infect Dis 162: 1283-1290.

Howidi M, Rajah J, Abushrar Z, Parsons H 2007. The severity of respiratory syncytial virus bronchiolitis in young infants in the United arab emirates. J Trop Pediatr 53: 22-26.

Imaz MS, Sequeira MD, Videla C, Veronessi I, Cociglio R, Zerbini E, Carballal G 2000. Clinical and epidemiologic characteristics of respiratory syncytial virus subgroups A and B infections in Santa Fe, Argentina. J Med Virol 61: 76-80.

Johansen J, Christensen LS, Hornsleth A, Klug B, Hansen KS, Nir M 1997. Restriction pattern variability of respiratory syncytial virus during three consecutive epidemics in Denmark. Apmis 105: 303-308.

Martinello RA, Chen MD, Weibel C, Kahn JS 2002. Correlation between respiratory syncytial virus genotype and severity of illness. J Infect Dis 186: 839-842.

Mello W, Silva C 1992. Epidemiological aspects of RSV subgroups in Belém, Brazil. Boletin Latino-americano 1: 8.

Moura FE, Borges LC, Portes SA, Ramos EA, Siqueira MM 2003. Respiratory syncytial virus infections during an epidemic period in Salvador, Brazil. Viral antigenic group analysis and description of clinical and epidemiological aspects. Mem Inst Oswaldo Cruz 98: 739-743.

Mufson MA, Belshe RB, Orvell C, Norrby E 1987. Subgroup char- 
acteristics of respiratory syncytial virus strains recovered from children with two consecutive infections. J Clin Microbiol 25: 1535-1539.

Mufson MA, Belshe RB, Orvell C, Norrby E 1988. Respiratory syncytial virus epidemics: variable dominance of subgroups A and B strains among children, 1981-1986. J Infect Dis 157: 143-148.

Palomino MMA, Larenas A J, Moraga AG, Avendano LF 2004. Severidad clínica de la infección respiratoria aguda baja primaria por virus respiratorio sincicial grupos A y B. Rev Chil Pediatr 75: $18-24$.

Papadopoulos NG, Gourgiotis D, Javadyan A, Bossios A, Kallergi K, Psarras S, Tsolia MN, Kafetzis D 2004. Does respiratory syncytial virus subtype influences the severity of acute bronchiolitis in hospitalized infants? Respir Med 98: 879-882.

Park JW, Barnett DW 2002. Respiratory syncytial virus infection and the primary care physician. South Med J 95: 353-357.

Parrott RH, Kim HW, Brandt CD, Chanock RM 1974. Respiratory syncytial virus in infants and children. Prev Med 3: 473-480.

Peret TC, Hall CB, Schnabel KC, Golub JA, Anderson LJ 1998. Circulation patterns of genetically distinct group A and B strains of human respiratory syncytial virus in a community. $J$ Gen Virol 79: 2221-2229.

Queiróz DAO, Durigon EL, Botosso VF, Ejzemberg B, Vieira SE, Mineo JR, Yamashita C, Hein N, Lopes CL, Cacharo AL, Stewien KE 2002. Immune response to respiratory syncytial virus in young Brazilian children. Braz J Med Biol Res 35: 1183-1193.

Sangaré L, Curtis MP, Ahmad S 2006. Hospitalization for respiratory syncytial virus among California infants: disparities related to race, insurance, and geography. J Pediatr 149: 373-377.

Savon C, Goyenechea A, Valdes O, Aguilar J, Gonzalez G, Palerm L, Gonzalez G, Perez Brena P 2006. Respiratory syncytial virus group A and B genotypes and disease severity among Cuban children. Arch Med Res 37: 543-547.
Simoes EA 2001. Treatment and prevention of respiratory syncytial virus lower respiratory tract infection. Long-term effects on respiratory outcomes. Am J Respir Crit Care Med 163: S14-17.

Siqueira MM, Nascimento JP, Anderson LJ 1991. Antigenic characterization of respiratory syncytial virus group A and B isolates in Rio de Janeiro, Brazil. J Clin Microbiol 29: 557-559.

Stockton J, Ellis JS, Saville M, Clewley JP, Zambon MC 1998. Multiplex PCR for typing and subtyping influenza and respiratory syncytial viruses. J Clin Microbiol 36: 2990-2995.

Straliotto SM, Nestor SM, Siqueira MM 2001. Respiratory syncytial virus groups A and B in Porto Alegre, Brazil, from 1990 to 1995 and 1998. Mem Inst Oswaldo Cruz 96: 155-158.

Straliotto SM, Roitman B, Lima JB, Fischer GB, Siqueira MM 1994. Respiratory syncytial virus (RSV) bronchiolitis: comparative study of RSV groups A and B infected children. Rev Soc Bras Med Trop 27: 1-4.

Sullender WM 2000. Respiratory syncytial virus genetic and antigenic diversity. Clin Microbiol Rev 13: 1-15.

Vieira SE, Stewien KE, Queiróz DAO, Durigon EL, Torok TJ, Anderson LJ, Miyao CR, Hein N, Botosso VF, Pahl MM, Gilio AE, Ejzenberg B, Okay Y 2001. Clinical patterns and seasonal trends in respiratory syncytial virus hospitalizations in Sao Paulo, Brazil. Rev Inst Med Trop Sao Paulo 43: 125-131.

Walsh EE, McConnochie KM, Long CE, Hall CB 1997. Severity of respiratory syncytial virus infection is related to virus strain. $J$ Infect Dis 175: 814-820.

Welliver RC 2003. Review of epidemiology and clinical risk factors for severe respiratory syncytial virus (RSV) infection. $J$ Pediatr 143: S112-117.

WHO - World Heath Organization 1994. International Classification of Diseases, 10th Review, ICD-10, Available from: http://www. who.int/classifications/icd/en/.

Yun BY, Kim MR, Park JY, Choi EH, Lee HJ, Yun CK 1995. Viral etiology and epidemiology of acute lower respiratory tract infections in Korean children. Pediatr Infect Dis J 14: 1054-1059. 